\title{
Características Clínicas e Complicações do Transplante Haploidêntico com Ciclofosfamida Pós-Transplante: Implicações para a Enfermagem
}

doi: https://doi.org/10.32635/2176-9745.RBC.2020v66n1.361

\author{
Clinical Characteristics and Complications of the Haploidentical Transplantation with Post-Transplant Cyclophosphamide: \\ Implications for Nursing \\ Características Clínicas y Complicaciones del Trasplante Haploidéntico con Ciclofosfamida Post-Trasplante: Implicaciones \\ para la Enfermería
}

Valéria Fernandes de Souza Pinho'

Resumo

Introduçáo: $\mathrm{O}$ transplante haploidêntico (haplo) vem crescendo em números e se tornando uma alternativa viável para pacientes sem doadores compatíveis. Uma assistência de enfermagem qualificada também é muito importante para o seu sucesso. Portanto, torna-se necessário adquirir conhecimentos e habilidades no assunto. Objetivo: Descrever as características clínicas e complicaçôes do haplo com ciclofosfamida pós-transplante e discutir suas implicaçóes para a assistência de enfermagem. Método: Revisão integrativa da literatura publicada a partir de 2014, pesquisada nas bases da Biblioteca Virtual em Saúde com o descritor "haploidentical transplantation" e selecionada com critérios pré-definidos. Resultados: Vinte e cinco textos foram revisados; todos da área médica e compostos principalmente de estudos de coorte retrospectivos com amostras pequenas. Entre as características mais prevalentes, destacaram-se: a mãe como principal doadora para crianças ( $5 / 7$ estudos); regime não mieloablativo (52\%); e enxerto de sangue periférico (56\%). Além da doença enxerto versus hospedeiro e da rejeição, as complicaçôes mais descritas foram: cistite hemorrágica por vírus BK $(56 \%)$ e reativação do citomegalovírus (48\%); e as com maiores variações nas frequências foram mucosite ( $8 \%$ a $100 \%)$ e febre não infecciosa $(22 \%$ a $100 \%)$. As principais causas de mortalidade foram a recaída da doença $(3 \%$ a 35\%) e as infecçóes (3\% a 32\%). Conclusáo: Esta revisão alertou para a necessidade de aprimoramento da assistência na administração da ciclofosfamida pós-transplante, no suporte aos doadores e no manejo da febre não infecciosa, das infecçóes virais e da cistite hemorrágica, para que haja melhora na qualidade de vida dos pacientes e diminuição na morbidade e na mortalidade relacionadas ao haplo. Palavras-chave: Transplante Haploidêntico/efeitos adversos; Ciclofosfamida; Cuidados de Enfermagem.

\begin{abstract}
Introduction: Haploidentical Transplantation (haplo) has been growing in numbers and becoming a viable alternative for patients without compatible donors. Qualified nursing care is also very important for its success. Therefore, it becomes necessary to acquire knowledge and skills about the subject. Objective: To describe clinical characteristics and complications of haplo with post-transplant cyclophosphamide and discuss its implications for nursing care. Method: Integrative literature review published from 2014, searched in the bases of the "Biblioteca Virtual em Saúde" with the descriptor "haploidentical transplantation" and selected with predefined criteria. Results: Twenty-five texts were reviewed, all of them of the medical area and consisting mainly of retrospective cohort studies with small samples. Among the most prevalent characteristics, the following were outstanding: the mother as the main donor for children (5/7 studies); non-myeloablative regimen (52\%) and peripheral blood graft (56\%). In addition to graft versus host disease and rejection, the most described complications were: $\mathrm{BK}$ virus hemorrhagic cystitis (56\%) and reactivation of cytomegalovirus (48\%); and the ones with the highest variations in frequencies were mucositis (8\% to $100 \%)$ and noninfectious fever $(22 \%$ to $100 \%)$. The main causes of mortality were relapse of the disease (3\% to $35 \%$ ) and infections (3\% to $32 \%$ ). Conclusion: This review warned about the necessity of improving the care in the administration of post-cyclophosphamide, the support to donors and management of noninfectious fever, viral infections and hemorrhagic cystitis to improve the quality of life of patients and reduce haplo-related morbidity and mortality. Key words: Transplantation, Haploidentical/adverse effects; Cyclophosphamide; Nursing Care.
\end{abstract}

Resumen

Introducción: El diagnóstico precoz del riesgo nutricional puede mejorar el pronóstico de los pacientes onco-hematológicos. Objetivo: Describir el estado nutricional en los pacientes onco-hematológicos y evaluar los factores asociados al riesgo nutricional en los pacientes onco-hematológicos de un Hospital Universitario Terciario de Fortaleza - Ceará. Método: Estudio transversal que incluyó a 127 pacientes adultos internados. Los datos de diagnóstico clínico y demográfico fueron recolectados a través de análisis de prontuarios. El estado nutricional fue evaluado por el índice de masa corporal (IMC), circunferencia braquial (CB) y por la aplicación de la herramienta de clasificación de riesgo nutricional - NRS-2002. Resultados: Diferentes parámetros, hubo divergencias en el estado nutricional. La mayoría de la muestra presentaba riesgo nutricional de acuerdo con la evaluación de la NRS-2002 70,1\% ( $\mathrm{n}=89$ ), seguida por la CB 33,9\% (n=43) y por IMC 8,7\% (n=11). Se observó una correlación positiva significativa entre el IMC y la edad $[\mathrm{r}=0,313, \mathrm{p}<0,001]$ y $\mathrm{CB}[\mathrm{r}=0,846$, $\mathrm{p}<0,001]$. Se observó una asociación significativa NRS-2002 $\geq 3$, e IMC $<18,5 \mathrm{~kg} /$ $\mathrm{m}^{2}(\mathrm{p}=0,023)$ y CB desnutrida $(\mathrm{p}=0,001)$. Hubo asociación significativa entre $\mathrm{IMC}<18,5 \mathrm{~kg} / \mathrm{m}^{2}$ y CB desnutrida $(\mathrm{p}=0,001)$, y entre residir en zona urbana y presentar $\mathrm{CB}$ adecuado $(\mathrm{p}=0,023)$. Conclusión: Alta prevalencia de riesgo nutricional, así como una asociación significativa entre riesgo nutricional y bajos valores de IMC y CB, y residir en zonas rurales. Hay la necesidad de utilizar una combinación de indicadores para diagnosticar de forma más precisa y precoz el estado nutricional de estos pacientes.

Palabras clave: Trasplante Haploidéntico/efectos adversos; Ciclofosfamida; Atención de Enfermería.

${ }^{1}$ Centro de Transplante de Medula Óssea do Instituto Nacional de Câncer José Alencar Gomes da Silva (Cemo/INCA). Rio de Janeiro (RJ), Brasil. Orcid iD: https:// orcid. org/0000-0002-6823-0844

Endereço para correspondência: Valéria Fernandes de Souza Pinho. Rua Parú, 58 - Apto. 503 - Várzea. Teresópolis (RJ), Brasil. CEP $25963-002$. E-mail: vdesouzapinho@yahoo.com.br

Nota: Parte do conteúdo do manuscrito foi apresentada em uma sessão do XXII Congresso da SBTMO, realizado entre 2 e 4 de agosto de 2018 , no Rio de Janeiro. Posteriormente, essa parte foi aperfeiçoada e apresentada em duas aulas no Cemo/INCA, nos dias 23 e 30 de agosto de 2018 , como atividade do Programa de Educação Continuada em Enfermagem dessa unidade. Por fim, no dia 14 de novembro de 2018, foi apresentada na XII Jornada de Enfermagem Oncológica do INCA/XIX Congresso da SBEO. 


\section{INTRODUÇÃO}

As primeiras tentativas com o transplante haploidêntico (haplo) se deram nos anos 1970. Os resultados foram muito ruins em razão dos altos índices de rejeição do enxerto, ou das altas taxas de incidência da doença enxerto contra hospedeiro (DECH) grave, o que resultou em grande mortalidade relacionada ao tratamento. Ficou claro, portanto, que novas técnicas para ultrapassar a barreira da compatibilidade entre os antígenos leucocitários humanos (do inglês, human leukocyte antigens - HLA) eram necessárias. Os estudos e experimentos continuaram, mas, somente, há cerca de duas décadas, com o desenvolvimento de plataformas diferenciadas de imunossupressão, o haplo vem crescendo em números e em importância, e se apresentando como uma alternativa viável para pacientes sem doadores compatíveis ${ }^{1,2}$.

O haplo é definido pelos descritores em ciências da Biblioteca Virtual em Saúde (BVS) como um "transplante entre indivíduos que compartilham uma correspondência parcial de haplótipos"3. Ou seja, uma cópia idêntica de apenas um dos cromossomas 6 , que é onde são encontrados os genes que codificam o sistema HLA. Para que isso aconteça, é necessário que os doadores sejam familiares de primeiro, ou, eventualmente, de segundo graus. Contudo, eles ainda podem compartilhar com o paciente uma série de outros genes localizados no outro cromossoma 6 não idêntico, resultando, em muitos casos, em mais de $50 \%$ de compatibilidade ${ }^{1}$.

Para controle do desafio imposto pela incompatibilidade parcial, que acarreta uma alorreatividade intensa dos linfócitos $\mathrm{T}$ tanto do paciente quanto do doador, atualmente são empregadas três plataformas de imunossupressão. A primeira consiste na manipulação do enxerto para depleçáo total ou seletiva de células T, in vitro, com infusão de megadoses de células-tronco. A segunda emprega enxertos náo manipulados com a administração de imunoglobulina antitimocítica (do inglês, antithymocyte globulin - ATG). Seu protocolo mais conhecido é o GIAC, utilizado principalmente na China. Constitui-se da mobilização do doador com fator estimulador de colônias de granulócitos $(\mathrm{G})$; imunossupressão intensificada (I) pós-transplante com ciclosporina, metotrexato e micofenolato de mofetila; inclusão da ATG (A) no condicionamento e um enxerto combinado $(\mathrm{C})$ de medula óssea e sangue periférico ${ }^{1,2}$.

A terceira opção de imunossupressão, também para enxertos não manipulados, consiste na administração de altas doses de ciclofosfamida, $50 \mathrm{mg} / \mathrm{kg} / \mathrm{dia}$, geralmente nos dias +3 e +4 pós-transplante, e que tem como objetivo fazer, in vivo, uma depleção de células $\mathrm{T}$ alorreativas de forma bidirecional. Ao mesmo tempo, a droga inativa células $\mathrm{T}$ do receptor, diminuindo a probabilidade de rejeiçáo do enxerto e inativa células $\mathrm{T}$ do doador, diminuindo a incidência e a gravidade das $\mathrm{DECH}$ aguda e crônica ${ }^{1,2}$.

No presente momento, esta é a plataforma de imunossupressáo para o haplo mais utilizada no mundo inteiro. Primeiro, porque ela funciona, pois a ciclofosfamida é um potente imunossupressor. Segundo, porque não necessita de tecnologia e pessoal especializado como nos custosos processos de depleção de células T in vitro e, por isso, é mais barata e pode ser empregada em centros sem grandes recursos ${ }^{2}$. Terceiro, a droga tem grande disponibilidade e todas as equipes que fazem transplante de células-tronco hematopoéticas (TCTH) já têm familiaridade com o manejo de seus efeitos adversos.

Os resultados do haplo com ciclofosfamida pós-transplante têm sido comparados aos resultados do TCTH aparentado compatível padráo e dos alternativos não aparentados, sangue de cordão umbilical e haplos que empregam as outras duas plataformas de imunossupressão anteriormente descritas. De uma maneira geral, com algumas exceçóes, tem-se encontrado resultados semelhantes entre eles, no que diz respeito à sobrevida global. O haplo tende a ter uma menor mortalidade relacionada ao tratamento; mas, em contrapartida, um maior índice de recaída quando são empregados protocolos de condicionamento de intensidade reduzida. Contudo, a diferença fundamental está nas incidências das DECH aguda e principalmente da crônica que, no haplo com ciclofosfamida pós-transplante, têm se mostrado significativamente menores ${ }^{1}$.

Esses achados são relevantes e encorajadores, uma vez que a DECH é uma das complicaçôes que mais afetam negativamente a qualidade de vida dos pacientes transplantados. Eles também corroboram, cada vez mais, o haplo como uma alternativa viável para TCTH. Contudo, apesar do otimismo, são necessários cautela e estudos mais controlados, pois seus efeitos a longo prazo ainda não estão totalmente conhecidos e a maioria dos estudos atuais apresenta limitaçóes significativas como análise retrospectiva, comparaçóes não randomizadas e amostras pequenas.

Assim como para todos os tipos de transplante, uma assistência de enfermagem qualificada também é muito importante para o sucesso do haplo. Para tanto, torna-se necessário que a equipe adquira conhecimentos e habilidades relacionadas a essa alternativa de transplante ${ }^{4}$.

No transcurso de um TCTH, os principais focos de atenção da enfermagem são: a educação e a preparação de pacientes, doadores e familiares; a execução de procedimentos operacionais com conformidade; a 
administração dos regimes de condicionamento e de imunossupressão; a infusão do enxerto e o controle de complicaçóes imediatas, precoces e tardias relacionadas ao tratamento. No haplo, por ser uma modalidade ainda relativamente nova, é fundamental estar atento às suas características e complicaçóes específicas para aperfeiçoar o cuidado e, consequentemente, favorecer melhores resultados ${ }^{4}$.

Diante dessas considerações, esta revisão integrativa da literatura teve como objetivo descrever características clínicas e complicaçóes do haplo com ciclofosfamida pós-transplante e discutir suas implicaçôes para a assistência de enfermagem.

\section{MÉTODO}

A prática baseada em evidências tem gerado um aumento na produção das revisóes de literatura sistemática e de metanálise que, embora apresentem níveis de evidências fortes, não respondem a importantes questôes de enfermagem relacionadas aos cuidados e/ou ao impacto da doença ou do tratamento na qualidade de vida dos pacientes e de seus familiares. Nesse aspecto, a revisão integrativa é uma abordagem metodológica mais amplificada que permite a inclusão de dados da literatura teórica, empírica, experimental ou não, e até de material não publicado, a fim de proporcionar um conhecimento mais consistente e fundamentado em conceitos, teorias ou problemas de saúde relevantes para a profissãos.

Esta revisão integrativa foi baseada no método proposto por Souza et al. ${ }^{5}$ e desenvolvida nas seguintes etapas: formulação da questão norteadora; busca e seleção da literatura; extração dos dados; análise dos estudos; discussão dos resultados e apresentação da revisão.

Considerando-se o panorama atual do haplo e os principais focos de atenção da enfermagem em TCTH, formulou-se a seguinte questão: "Quais as principais características clínicas e complicaçôes do haplo com ciclofosfamida pós-transplante e como elas podem implicar na assistência de enfermagem?”

No mês de maio de 2019, foi realizado um processo de busca e seleçáo de estudos nas seguintes bases de dados da BVS Brasil: LILACS; MEDLINE e BDENF. O descritor utilizado foi "haploidentical transplantation/ transplante haploidêntico" e a combinação deste com "nursing" ou "nursing care" por meio dos conectores booleanos " $A N D$ " e "OR" na busca avançada.

A inclusão dos estudos foi feita por meio da aplicação dos seguintes filtros da própria BVS: descritor no título do artigo; texto completo disponível; ciclofosfamida como assunto principal; limite em humanos; espanhol, inglês ou português como idiomas; e publicaçóes a partir de 2014 (últimos 5 anos). Após a leitura dos títulos e dos resumos, ou de textos na íntegra, foram excluídos os estudos de revisão; os relatos de casos; os artigos pagos; e aqueles que não se aplicavam aos objetivos desta revisão (Figura 1).

Após a seleção, os dados sobre os estudos, as características clínicas das amostras, os resultados e as complicaçóes foram extraídos segundo uma adaptação do instrumento validado por Ursi (apud Souza et al..$^{5}$ ). As frequências das variáveis foram gerenciadas em uma planilha construída no Windows Excel 10.0 da Microsoft . Percentuais que não estavam explicitados nos resultados dos estudos foram calculados com base no tamanho da amostra de haplo com ciclofosfamida pós-transplante, independente de comparaçôes com outros tipos de TCTH ou outros tipos de imunossupressão. A fim de melhorar a confiabilidade dos dados, as informaçôes extraídas sobre as características e complicaçôes foram revisadas pela autora em um segundo momento.

Para embasar a discussão nesta revisão, foram consideradas como evidências as frequências das características clínicas e as complicaçóes que foram descritas em cinco (20\%) ou mais estudos. Os níveis de evidência foram hierarquizados segundo a classificação proposta por Stetler et al. ${ }^{6}$. Sáo eles: 1 metanálises de múltiplos estudos clínicos controlados; 2 - estudos experimentais individuais; 3 - estudos quase experimentais ou estudos de caso-controle pareados; 4 - estudos descritivos náo experimentais, estudos qualitativos ou de série de casos; 5 - relatos de casos ou de experiências; e 6 - opiniōes de especialistas ou de comitês de especialistas, regulamentos ou legislaçóes.

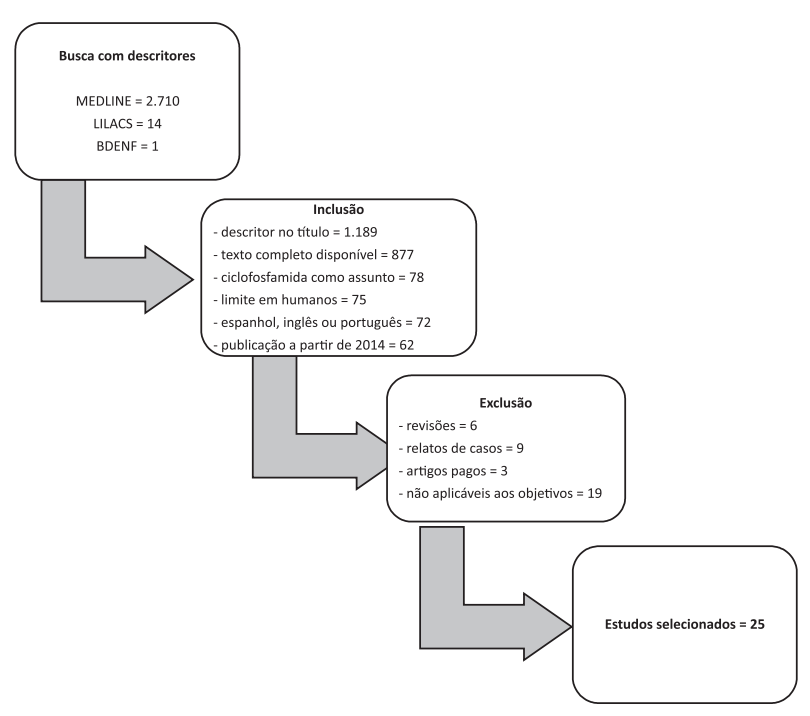

Figura 1. Fluxograma da busca e seleção dos estudos 


\section{RESULTADOS E DISCUSSÃO}

Todos os 25 textos selecionados foram da área médica, publicados em inglês e provenientes da base MEDLINE. Quinze (60\%) foram estudos de coorte observacionais retrospectivos, nível de evidência 4; e quatro $(16 \%)$ foram estudos clínicos, nível 2. Vinte e três (92\%) eram artigos originais e dois (8\%) eram cartas ao editor. Sete (28\%) foram oriundos dos Estados Unidos, sendo que três destes foram do grupo da Universidade/Hospital Johns Hopkins de Baltimore; grupo este que desenvolveu e consolidou em 2008 a plataforma pioneira de ciclofosfamida pós-transplante para o haplo 2 . Seis (24\%) foram provenientes de uma cooperação entre França e Itália; três (12\%) somente da Itália; dois (8\%) da Espanha; e um (4\%) de uma cooperação entre Estados Unidos e Colômbia. Brasil, Colômbia, Índia, Japão, México e Uruguai contribuíram com um (4\%) estudo cada.

Conforme os dados apresentados no Tabela $1^{7-31}$, o tamanho das amostras $(\mathrm{N})$ variou de 16 a 687 pacientes, sendo que em 14 (56\%) estudos o $\mathrm{N}$ foi menor que 50. A idade variou de 1 a 78 anos. Sete (28\%) estudos foram compostos por crianças, adolescentes e adultos jovens e dois (8\%) foram de idosos com 50 anos ou mais. $O$ gênero masculino foi o principal em 15/25 amostras. A maior parte dos diagnósticos foi de doenças onco-hematológicas, com maior frequência da leucemia mieloide aguda (44\%). Um estudo descreveu os resultados em tumores sólidos pediátricos ${ }^{28}$ e um outro em anemia de Fanconi ${ }^{23}$.

O haplo foi empregado como primeiro, segundo e até terceiro transplante. Os estágios de doença foram os mais diferentes possíveis: baixo, médio e alto risco; remissão completa, parcial, em recaída ou em progressão; refratária; localizada ou extensa. Exclusivamente, em um dos estudos, o haplo foi avaliado como terapia de resgate para recaída após transplantes totalmente compatíveis ${ }^{16}$.

Quanto aos doadores, $40 \%$ dos estudos não os especificaram; nas amostras de adultos e idosos, os irmáos e os filhos foram mais frequentes; nas amostras pediátricas, a máe foi a principal doadora em 5/7 estudos. O regime de condicionamento não mieloablativo foi o mais frequente em $52 \%$ dos estudos e a quase totalidade destes foi baseada na plataforma de Baltimore, representada no Tabela 2. O enxerto de sangue periférico foi o único ou o principal em $56 \%$ das amostras. Em quatro (16\%), o haplo foi realizado em regime de hospital-dia; dois destes descreveram que $60 \%{ }^{9}$ e $84 \%^{13}$ dos pacientes necessitaram de internação para controle de complicações.

Vinte e dois estudos (88\%) objetivaram como desfechos primários as estimativas de sobrevida, mortalidade, recaída, enxertia e $\mathrm{DECH}$. O período médio de seguimento variou de sete a 48 meses; a sobrevida global, no maior tempo estimado, variou de $21 \%$ a $73 \%$; a incidência cumulativa de recaída de $15 \%$ a $81 \%$; e a mortalidade relacionada ao tratamento de $6 \%$ a $36 \%$. A média de pega de neutrófilos variou de 13 a 21 dias e a de plaquetas de 14 a 35 dias. Nos outros três estudos, os desfechos primários foram, em cada um deles, febre ${ }^{12}$, infecçôes ${ }^{21}$ e cistite hemorrágica viral ${ }^{30}$.

A incidência da DECH foi investigada em $92 \%$ dos estudos. A frequência da DECH aguda graus II-IV variou de $14 \%$ a $70 \%$; a DECH aguda graus III-IV de $2 \%$ a $33 \%$; e a DECH crônica de $4 \%$ a $67 \%$. Já a rejeição primária (falência) do enxerto foi investigada em $72 \%$ dos estudos e a sua incidência variou de $<1 \%$ a $15 \%$. As outras complicaçóes descritas, apresentadas no Tabela 3 , foram por toxicidade do tratamento ou infecciosas, sendo a reativação do citomegalovírus $(\mathrm{CMV})$ e a cistite hemorrágica por vírus BK (iniciais do nome do primeiro paciente onde o vírus foi isolado) as mais descritas.

As principais causas de mortalidade foram a recaída da doença com uma variação de $3 \%$ a $35 \%$; as infecçôes de $3 \%$ a $32 \%$; a DECH de $1 \%$ a $17 \%$ e a falência única ou de múltiplos órgãos de 3\% a 7\%.

A DECH e a rejeição do enxerto foram, como desfechos preocupantes em transplantes incompatíveis, as complicaçóes mais investigadas nos estudos revisados. Contudo, com a plataforma de ciclofosfamida pós-transplante, estas náo parecem ser problemas maiores no haplo ${ }^{1}$. A mucosite também apresentou frequências altas em alguns estudos ${ }^{14,23}$, mas o uso de regimes não mieloablativos tem diminuído a sua gravidade. Estas são complicações mais discutidas na literatura em TCTH e possuem protocolos ou guidelines de controle definidos.

Além da própria ciclofosfamida pós-transplante, outras características e complicaçóes também foram mais descritas e/ou apresentaram frequências mais altas. Por isso, foram consideradas também significativas e emergiram como temas para discussão. Uma vez que o processo de busca e seleção não resultou em nenhum estudo de enfermagem específico sobre o haplo, além dos dados apresentados, essa discussáo também foi baseada na integração com alguma literatura sobre TCTH em geral e com a experiência pessoal da autora.

A plataforma pioneira com ciclofosfamida pós-transplante de Baltimore surtiu efeitos satisfatórios na prevenção da $\mathrm{DECH}$ e vem sendo replicada em vários estudos e instituições. Contudo, vem sofrendo modificações ao longo dos últimos anos como intensificação do regime de condicionamento, uso de enxerto de sangue periférico no lugar do de medula óssea e administraçáo dos inibidores de calcineurina e do micofenolato antes da ciclofosfamida. Também não é mais exclusiva para o haplo e tem sido investigada como terapia imunossupressora única ou combinada nos TCTH totalmente compatíveis, e até 
Tabela 1. Características clínicas nos estudos revisados

\begin{tabular}{|c|c|c|c|}
\hline Números & $\begin{array}{l}\text { Características do estudo: } \\
\text { autor/ano/país de origem/tipo }\end{array}$ & $\begin{array}{l}\text { Características } \\
\text { da amostra }\end{array}$ & $\begin{array}{l}\text { Características } \\
\text { do haplo }\end{array}$ \\
\hline 1 & $\begin{array}{l}\text { Castagna et al. }{ }^{7}, 2014 \\
\text { França e Itália } \\
\text { ECOR bicêntrico }\end{array}$ & $\begin{array}{l}\mathrm{N}=69 \\
\text { Idade }^{\mathrm{a}}=44(19-68) \\
\text { Gênero }^{\circ} \mathrm{NE} \\
\text { Diag. }^{\mathrm{b}}=\mathrm{LH}(42 \%)\end{array}$ & $\begin{array}{l}\text { Doador }^{b}=\text { NE } \\
\text { Regime }^{b}=\text { NMA }(100 \%) \\
\text { Enxerto }^{b}=\text { MO }(67 \%)\end{array}$ \\
\hline 2 & $\begin{array}{l}\text { Sugita et al. }{ }^{8}, 2015 \\
\text { Japão } \\
\text { ECP multicêntrico }\end{array}$ & $\begin{array}{l}\mathrm{N}=31 \\
\text { Idade }=48(21-65) \\
\text { Gênero M/F = 22/9 } \\
\text { Diag. = LMA (55\%) }\end{array}$ & $\begin{array}{l}\text { Doador }=\text { Filho }(45 \%) \\
\text { Regime }=\text { IR }(100 \%) \\
\text { Enxerto }=\text { SP }(100 \%)\end{array}$ \\
\hline 3 & $\begin{array}{l}\text { Kasamon et al. }{ }^{9}, 2015 \\
\text { Estados Unidos } \\
\text { ECOR unicêntrico }\end{array}$ & $\begin{array}{l}\mathrm{N}=271 \\
\text { Idade }=61(50-75) \\
\text { Gênero M/F }=184 / 87 \\
\text { Diag. = LNH }(47 \%)\end{array}$ & $\begin{array}{l}\text { Doador }=\text { NE } \\
\text { Regime }=\text { NMA }(100 \%) \\
\text { Enxerto }=\text { MO }(100 \%)\end{array}$ \\
\hline 4 & $\begin{array}{l}\text { Cieri et al. }{ }^{10}, 2015 \\
\text { Itália } \\
\text { ECP unicêntrico }\end{array}$ & $\begin{array}{l}\mathrm{N}=40 \\
\text { ldade }=55(21-78) \\
\text { Gênero M/F }=23 / 17 \\
\text { Diag. = LMA }(55 \%)\end{array}$ & $\begin{array}{l}\text { Doador }=\text { Filho }(55 \%) \\
\text { Regime }=\text { MA }(100 \%) \\
\text { Enxerto }=\text { SP }(100 \%)\end{array}$ \\
\hline 5 & $\begin{array}{l}\text { Bacigalupo et al. }{ }^{11}, 2015 \\
\text { Itália } \\
\text { ECO unicêntrico }\end{array}$ & $\begin{array}{l}\mathrm{N}=148 \\
\text { Idade = } 47(17-74) \\
\text { Gênero = NE } \\
\text { Diag. = LMA (32\%) }\end{array}$ & $\begin{array}{l}\text { Doador }=\text { NE } \\
\text { Regime }=\text { MA }(100 \%) \\
\text { Enxerto }=M O(100 \%)\end{array}$ \\
\hline 6 & $\begin{array}{l}\text { Arango e Combariza }{ }^{12}, 2017 \\
\text { Colômbia } \\
\text { Estudo de série de casos } \\
\text { retrospectivos unicêntrico }\end{array}$ & $\begin{array}{l}\mathrm{N}=40 \\
\text { ldade = } 18(1-59) \\
\text { Gênero = NE } \\
\text { Diag. = LLA (50\%) }\end{array}$ & $\begin{array}{l}\text { Doador }=\text { Pai }(55 \%) \\
\text { Regime }=\text { NMA }(60 \%) \\
\text { Enxerto }=\text { SP }(100 \%)\end{array}$ \\
\hline 7 & $\begin{array}{l}\text { González-Llano et al. }{ }^{13}, 2016 \\
\text { México } \\
\text { ECOR unicêntrico }\end{array}$ & $\begin{array}{l}N=25 \text { ldade }=10(1-21) \\
\text { Gênero } M / F=17 / 8 \\
\text { Diag. }=\text { LLA }(72 \%)\end{array}$ & $\begin{array}{l}\text { Doador }=\text { Mãe }(80 \%) \\
\text { Regime }=\mathrm{NE} \\
\text { Enxerto }=\mathrm{SP}(100 \%)\end{array}$ \\
\hline 8 & $\begin{array}{l}\text { Jaiswal et al. }{ }^{14}, 2016 \\
\text { Índia } \\
\text { ECP unicêntrico }\end{array}$ & $\begin{array}{l}\mathrm{N}=20 \\
\text { Idade }=12(2-20) \\
\text { Gênero } M / F=12 / 8 \\
\text { Diag. = LMA }(65 \%)\end{array}$ & $\begin{array}{l}\text { Doador }=\text { Mãe }(70 \%) \\
\text { Regime }=\text { MA }(100 \%) \\
\text { Enxerto }=\text { SP }(100 \%)\end{array}$ \\
\hline 9 & $\begin{array}{l}\text { Devillier et al. }{ }^{15}, 2017 \\
\text { França e Itália } \\
\text { NE bicêntrico }\end{array}$ & $\begin{array}{l}\mathrm{N}=46 \\
\text { ldade = } 61(50-73) \\
\text { Gênero = NE } \\
\text { Diag. = LNH }(35 \%)\end{array}$ & $\begin{array}{l}\text { Doador }=\text { NE } \\
\text { Regime }=\text { NMA }(100 \%) \\
\text { Enxerto }=\text { SP }(100 \%)\end{array}$ \\
\hline 10 & $\begin{array}{l}\text { Gorgeis et al. }{ }^{16}, 2016 \\
\text { Estados Unidos } \\
\text { ECOR unicêntrico }\end{array}$ & $\begin{array}{l}\mathrm{N}=20 \\
\text { Idade }=54(21-66) \\
\text { Gênero M/F = 13/7 } \\
\text { Diag. = LMA (35\%) }\end{array}$ & $\begin{array}{l}\text { Doador }=\text { NE } \\
\text { Regime }=\text { NMA }(85 \%) \\
\text { Enxerto }=\text { SP }(55 \%)\end{array}$ \\
\hline 11 & $\begin{array}{l}\text { Rashidi et al. }{ }^{17}, 2016 \\
\text { Estados Unidos } \\
\text { ECOR unicêntrico }\end{array}$ & $\begin{array}{l}\mathrm{N}=62 \\
\text { Idade = } 54(19-73) \\
\text { Gênero } M / F=30 / 32 \\
\text { Diag. = LMA }(100 \%)\end{array}$ & $\begin{array}{l}\text { Doador }=\text { NE } \\
\text { Regime }=\text { IR }(56 \%) \\
\text { Enxerto }=\text { SP }(100 \%)\end{array}$ \\
\hline 12 & $\begin{array}{l}\text { Devillier et al. }{ }^{18}, 2016 \\
\text { França e Itália } \\
\text { ECOR bicêntrico }\end{array}$ & $\begin{array}{l}\mathrm{N}=60 \\
\text { ldade = } 57(22-73) \\
\text { Gênero = NE } \\
\text { Diag. = LMA (68\%) }\end{array}$ & $\begin{array}{l}\text { Doador }=\text { NE } \\
\text { Regime }=\text { IR }(67 \%) \\
\text { Enxerto }=\operatorname{SP}(80 \%)\end{array}$ \\
\hline 13 & $\begin{array}{l}\text { Dufort et al. }{ }^{19}, 2016 \\
\text { Uruguai } \\
\text { ECOR unicêntrico }\end{array}$ & $\begin{array}{l}\mathrm{N}=23 \\
\text { Idade }=15(1-26) \\
\text { Gênero } M / F=13 / 10 \\
\text { Diag. = LLA }(52 \%)\end{array}$ & $\begin{array}{l}\text { Doador }=\text { Mãe }(74 \%) \\
\text { Regime }=\text { MA }(70 \%) \\
\text { Enxerto }=\text { SP }(100 \%)\end{array}$ \\
\hline 14 & $\begin{array}{l}\text { Berger et al. }{ }^{20}, 2016 \\
\text { Itália } \\
\text { ECOR multicêntrico }\end{array}$ & $\begin{array}{l}\mathrm{N}=33 \\
\text { Idade }=12(1-21) \\
\text { Gênero } M / F=20 / 13 \\
\text { Diag. = LLA }(45 \%)\end{array}$ & $\begin{array}{l}\text { Doador }=\text { Mãe }(54 \%) \\
\text { Regime }=\text { NMA }(57 \%) \\
\text { Enxerto }=\text { MO }(91 \%)\end{array}$ \\
\hline 15 & $\begin{array}{l}\text { Slade et al. }{ }^{21}, 2017 \\
\text { Estados Unidos } \\
\text { ECOR unicêntrico }\end{array}$ & $\begin{array}{l}\mathrm{N}=104 \\
\text { ldade = } 50(19-73) \\
\text { Gênero } M / F=57 / 47 \\
\text { Diag. = LMA }(67 \%)\end{array}$ & $\begin{array}{l}\text { Doador }=\text { NE } \\
\text { Regime }=\text { NMA }(59 \%) \\
\text { Enxerto }=\text { SP }(100 \%)\end{array}$ \\
\hline
\end{tabular}


Tabela 1. continuação

\begin{tabular}{|c|c|c|c|}
\hline Números & $\begin{array}{l}\text { Características do estudo: } \\
\text { autor/ano/país de origem/tipo }\end{array}$ & $\begin{array}{l}\text { Características } \\
\text { da amostra }\end{array}$ & $\begin{array}{l}\text { Características } \\
\text { do haplo }\end{array}$ \\
\hline 16 & $\begin{array}{l}\text { Castagna et al. }{ }^{22}, 2017 \\
\text { França e Itália } \\
\text { ECOR multicêntrico }\end{array}$ & $\begin{array}{l}\mathrm{N}=30 \\
\text { ldade }=56(31-65) \\
\text { Gênero } M / F=13 / 17 \\
\text { Diag. = MM (100\%) }\end{array}$ & $\begin{array}{l}\text { Doador }=\text { Filho }(63 \%) \\
\text { Regime }=\text { MA }(53 \%) \\
\text { Enxerto }=\text { MO }(60 \%)\end{array}$ \\
\hline 17 & $\begin{array}{l}\text { Bonfim et al. }{ }^{23}, 2017 \\
\text { Brasil } \\
\text { ECO unicêntrico }\end{array}$ & $\begin{array}{l}\mathrm{N}=30 \\
\text { Idade }=10(4-16) \\
\text { Gênero } M / F=22 / 8 \\
\text { Diag. = Anemia de Fanconi } \\
(100 \%)\end{array}$ & $\begin{array}{l}\text { Doador }=\text { Mãe }(67 \%) \\
\text { Regime }=\text { NMA }(100 \%) \\
\text { Enxerto }=\text { MO }(100 \%)\end{array}$ \\
\hline 18 & $\begin{array}{l}\text { Castagna et al. }{ }^{24}, 2017 \\
\text { França e Itália } \\
\text { NE }\end{array}$ & $\begin{array}{l}\mathrm{N}=62 \\
\text { ldade = } 31(19-68) \\
\text { Gênero } M / F=36 / 26 \\
\text { Diag. = LH }(100 \%)\end{array}$ & $\begin{array}{l}\text { Doador }=\text { Irmão }(55 \%) \\
\text { Regime }=\text { NMA }(81 \%) \\
\text { Regime }=\text { MO }(63 \%)\end{array}$ \\
\hline 19 & $\begin{array}{l}\text { Srour et al. }{ }^{25}, 2017 \\
\text { Estados Unidos e Colômbia } \\
\text { ECOR multicêntrico }\end{array}$ & $\begin{array}{l}\mathrm{N}=109 \\
\text { Idade = } 32(18-66) \\
\text { Gênero = 64/45 } \\
\text { Diag. = LLA }(100 \%)\end{array}$ & $\begin{array}{l}\text { Doador }=\text { Irmão }(49 \%) \\
\text { Regime }=\text { MA }(64 \%) \\
\text { Enxerto }=\text { SP }(54 \%)\end{array}$ \\
\hline 20 & $\begin{array}{l}\text { Bashey et al. }{ }^{26}, 2017 \\
\text { Estados Unidos } \\
\text { ECO prospectivo multicêntrico }\end{array}$ & $\begin{array}{l}\mathrm{N}=687 \\
\text { Idade }=47(18-76) \\
\text { Gênero M/F }=394 / 293 \\
\text { Diag. = LMA }(44 \%)\end{array}$ & $\begin{array}{l}\text { Doador }=\text { NE } \\
\text { Regime }=\text { NMA }(72 \%) \\
\text { Enxerto }=\text { MO }(72 \%)\end{array}$ \\
\hline 21 & $\begin{array}{l}\text { Klein et al. }{ }^{27}, 2017 \\
\text { Estados Unidos } \\
\text { ECOR unicêntrico }\end{array}$ & $\begin{array}{l}\mathrm{N}=40 \\
\text { ldade = } 20(1-25) \\
\text { Gênero } M / F=28 / 12 \\
\text { Diag. = LH (35\%) }\end{array}$ & $\begin{array}{l}\text { Doador }=\text { Pai }(50 \%) \\
\text { Regime }=\text { NMA }(95 \%) \\
\text { Enxerto }=\text { MO }(95 \%)\end{array}$ \\
\hline 22 & $\begin{array}{l}\text { Llosa et al. }{ }^{28}, 2017 \\
\text { Estados Unidos } \\
\text { ECP unicêntrico }\end{array}$ & $\begin{array}{l}\mathrm{N}=16 \\
\text { ldade = } 18(3-26) \\
\text { Gênero M/F = 8/8 } \\
\text { Diag. = RMS (38\%) }\end{array}$ & $\begin{array}{l}\text { Doador }=\text { Pai }(94 \%) \\
\text { Regime }=\text { IR }(100 \%) \\
\text { Enxerto }=\text { MO }(100 \%)\end{array}$ \\
\hline 23 & $\begin{array}{l}\text { Esquirol et al. }{ }^{29}, 2017 \\
\text { Espanha } \\
\text { ECOR multicêntrico }\end{array}$ & $\begin{array}{l}\mathrm{N}=81 \\
\text { ldade = } 53(18-70) \\
\text { Gênero M/F = 40/41 } \\
\text { Diag. = LMA (36\%) }\end{array}$ & $\begin{array}{l}\text { Doador }=\text { Filho }(47 \%) \\
\text { Regime }=\text { MA }(100 \%) \\
\text { Enxerto }=\text { SP }(62 \%)\end{array}$ \\
\hline 24 & $\begin{array}{l}\text { Rimondo et al. }{ }^{30}, 2017 \\
\text { França e Itália } \\
\text { ECOR bicêntrico }\end{array}$ & $\begin{array}{l}\mathrm{N}=161 \\
\text { ldade = 53 (19-73) } \\
\text { Gênero = NE } \\
\text { Diag. = NE }\end{array}$ & $\begin{array}{l}\text { Doador }=\text { NE } \\
\text { Regime }=\text { NMA }(69 \%) \\
\text { Enxerto }=\text { MO }(52 \%)\end{array}$ \\
\hline 25 & $\begin{array}{l}\text { Kwon et al. }{ }^{31}, 2017 \\
\text { Espanha } \\
\text { ECOR multicêntrico }\end{array}$ & $\begin{array}{l}\mathrm{N}=36 \\
\text { Idade = } 38(21-65) \\
\text { Gênero } M / F=21 / 15 \\
\text { Diag. LMA (100\%) }\end{array}$ & $\begin{array}{l}\text { Doador }=\text { Irmão }(36 \%) \\
\text { Regime }=\text { MA }(100 \%) \\
\text { Enxerto }=\text { SP }(97 \%)\end{array}$ \\
\hline
\end{tabular}

Legendas: ${ }^{\text {a }}$ - idade média e variaçáo; ${ }^{\mathrm{b}}$ - tipo mais frequente; ECOR - estudo de coorte observacional retrospectivo; ECP - estudo clínico prospectivo; ECO - estudo de coorte observacional; $\mathrm{N}$ - tamanho da amostra; M/F - masculino/feminino; NE - não especificado; Diag. - diagnóstico; LMA - leucemia mieloide aguda; LLA leucemia linfoblástica aguda; LH - linfoma de Hodgkin; LNH - linfoma não Hodgkin; MM - mieloma múltiplo; RMS - rabdomiosarcoma; MA - mieloablativo; NMA - não mieloablativo; IR - intensidade reduzida; MO - medula óssea; SP - sangue periférico.

experimentada em transplantes conjuntos de rim com medula óssea ${ }^{1,8,11,15,17}$.

Para ser eficaz na prevenção da rejeição do enxerto e da DECH, recomenda-se que a primeira dose da ciclofosfamida seja administrada em um intervalo de dois a três dias após a infusão do enxerto. Mais precisamente, em termos operacionais, entre 60 e 72 horas após. Estudos com animais têm demonstrado que, nesse período, as células $\mathrm{T}$ maduras estáo em franco processo de divisão celular e no pico de síntese de DNA, quando a droga é mais atuante. Se for administrada antes de 24 horas ou depois de 96 horas, seu efeito indutor de tolerância alogênica pode ser comprometido ${ }^{1,20}$. Portanto, a enfermagem deve entrar em entendimento com o serviço de farmácia e preparar o paciente para que receba a droga dentro desse intervalo de tempo.

Por ser de alta dose, a ciclofosfamida pós-transplante pode causar cistite hemorrágica química. A hiper-hidratação durante e até pelo menos 24 horas após a administração da droga e a diurese forçada com diuréticos, 
Tabela 2. Plataforma de ciclofosfamida pós-transplante de Baltimore, Estados Unidos

\begin{tabular}{|c|c|}
\hline Drogas, irradiação e doses & $\begin{array}{c}\text { Dias na linha } \\
\text { do trans- } \\
\text { plante }\end{array}$ \\
\hline Ciclofosfamida $14,5 \mathrm{mg} / \mathrm{kg} / \mathrm{dia}$ & -6 e -5 \\
\hline Fludarabina $30 \mathrm{mg} / \mathrm{m}^{2} /$ dia & $-6 a-2$ \\
\hline Irradiação corporal total 200 cGy & -1 \\
\hline Infusão do enxerto de medula óssea & 0 \\
\hline Ciclofosfamida 50 mg/kg/dia & $+3 \mathrm{e}+4$ \\
\hline Filgrastima $5 \mathrm{mcg} / \mathrm{kg} / \mathrm{dia}$ & $\begin{array}{c}+5 \text { até a pega } \\
\text { medular }\end{array}$ \\
\hline Micofenolato 15 mg/kg, 3 vezes/dia & +5 até +35 \\
\hline Tacrolimo 0,015 mg/kg, 2 vezes/dia & +5 até +180 \\
\hline
\end{tabular}

Fonte: Adaptado de Klein et al. ${ }^{27}$.

Tabela 3. Complicações descritas nos estudos revisados

\begin{tabular}{|c|c|c|}
\hline Complicações & $\begin{array}{l}\text { Frequência } \\
\text { nos } \\
\text { estudos \% }\end{array}$ & $\begin{array}{c}\text { Variação } \\
\text { de } \\
\text { frequência } \\
\text { nas } \\
\text { amostras } \\
\%^{\text {Ref. }}\end{array}$ \\
\hline $\begin{array}{l}\text { 1- Cistite hemorrágica } \\
\text { pelo vírus } \mathrm{BK} \text { e outros }\end{array}$ & 56 & $7^{7,30}$ a $50^{23}$ \\
\hline $\begin{array}{l}\text { 2- Viremia ou reativação } \\
\text { do } C M V\end{array}$ & 48 & $33^{22}$ a $75^{23}$ \\
\hline 3- Doença pelo CMV & 32 & $3^{22}$ a $15^{10,21}$ \\
\hline $\begin{array}{l}\text { 4- Infecções fúngicas em } \\
\text { geral }\end{array}$ & 32 & $5^{14}$ a $25^{3,28}$ \\
\hline $\begin{array}{l}\text { 5- Viremia, reativação ou } \\
\text { doença pelo EBV }\end{array}$ & 28 & $3^{20,31}$ a $23^{24}$ \\
\hline $\begin{array}{l}\text { 6- Viremia ou doença por } \\
\text { outros vírus }\end{array}$ & 24 & $3^{20}$ a $65^{10}$ \\
\hline $\begin{array}{l}\text { 7- Infecções bacterianas } \\
\text { em geral }\end{array}$ & 24 & $13^{10}$ a $62^{21}$ \\
\hline $\begin{array}{l}\text { 8- Síndrome de obstrução } \\
\text { sinusoidal }\end{array}$ & 24 & $1^{29}$ a $17^{19}$ \\
\hline 9- Mucosite & 20 & $8^{13}$ a $100^{14}$ \\
\hline $\begin{array}{l}\text { 10- Neutropenia febril ou } \\
\text { febre infecciosa }\end{array}$ & 20 & $18^{7}$ a $87^{21}$ \\
\hline 11 - Febre não infecciosa & 20 & $22^{28}$ a $100^{8}$ \\
\hline
\end{tabular}

Legendas: CMV - citomegalovírus; EBV - vírus Epstein-Barr.

se for necessária, são as principais medidas de prevenção da complicação. Nos estudos revisados, também foi frequente o uso do medicamento uroprotetor mesna ${ }^{8-11,13,18,22,28,29}$. Cabe à enfermagem administrá-lo rigorosamente, nos horários estabelecidos, antes e até 12 a 24 horas após a ciclofosfamida, conforme o protocolo institucional ${ }^{32}$.

Outros cuidados são estimular micçóes em períodos curtos e frequentes; monitorizar o aspecto e volume da diurese; colher amostra de urina para exames em caso de sinais e sintomas suspeitos e acompanhar os níveis de eletrólitos e da função renal. A orientação do paciente sobre a administração da ciclofosfamida e a importância de relatar, prontamente, sintomas de cistite é fundamental para a aplicação de intervençóes precoces para o seu controle ${ }^{32}$.

Outra medida também recomendada é que se deva evitar a administraçáo, entre os dias -1 e +5 , de glicocorticoides. Eles podem comprometer o efeito imunossupressor da ciclofosfamida e só devem ser empregados em casos emergenciais e a critério médico ${ }^{1,8,12}$.

A máe como principal doadora para crianças caracteriza uma personagem com ambivalência de papéis: cuidadora e doadora. Na internação, comumente é a mãe que vem como cuidadora principal da criança. No dia do transplante, vai para o centro cirúrgico ou setor de aféreses doar as células-tronco. Quando volta, é cuidada pela equipe. No dia seguinte, quando recebe alta e deveria ir para sua residência se recuperar do processo de doação, ela permanece com a criança, assumindo, ou pelo menos tentando assumir, seu papel de cuidadora. Além de todos os problemas que ela já tem, existem também a dor, a fadiga e as limitaçóes impostas pela doação. Contudo, por ser mãe e mesmo que tenha outras pessoas que lhe deem suporte, não quer abrir mão de cuidar do filho. Para ela, o gesto de doar pode ter o simbolismo de estar dando a vida ao filho pela segunda vez e pode sentir-se responsável pelos resultados do transplante ${ }^{33}$.

A criança, como personagem principal desse contexto, está sofrendo efeitos adversos físicos, emocionais, cognitivos e sociais do transplante, que, consequentemente, comprometem sua qualidade de vida. Pode até experimentar sintomas de depressão e ansiedade em decorrência da complexidade do tratamento, mas também costuma expressar preocupaçóes com o bem-estar da sua mãe. Existe uma forte relação deste último aspecto com a adaptaçáo da criança ao processo do TCTH, e a equipe de saúde precisa estar atenta a isso ${ }^{33}$.

A enfermagem, a priori, pode ter um pouco mais de trabalho na administração de medicamentos e curativos, mas também muitas preocupaçôes; pois trata-se de um "segundo" paciente no quarto, com riscos de infecção, queda, sangramento ${ }^{33}$ e, conforme o estudo de Halter et al. ${ }^{34}$, um mínimo, mas real, risco de eventos adversos graves e até de morte. Essas complicaçóes sustentam a importância de uma avaliação prévia criteriosa e do acompanhamento dos doadores nos períodos imediatos, precoces e tardios após a doação. Portanto, especial atenção deve ser dada a essa mãe durante todo o período de acompanhamento do filho.

Ainda nesse contexto, não se pode deixar de considerar que, por apresentar limitaçôes, ela também pode solicitar ou mesmo exigir que sejam feitas exceçóes às regras do serviço. Isso pode requerer alteraçôes nas rotinas e gerar conflitos com a equipe de enfermagem. Além do mais, nas 
situaçôes em que a evolução do transplante é desfavorável, como por exemplo, falência de enxerto, a mãe pode apresentar sentimento de culpa e a tensão no ambiente pode aumentar ${ }^{33}$.

No sentido de controlar, quando possível, esses problemas, a enfermagem deve procurar preparar de forma mais adequada o paciente e a sua família para o haplo. É de grande utilidade quando eles assistem reunióes educativas, fazem a consulta de enfermagem e podem conhecer previamente a unidade de internação com esclarecimentos sobre o procedimento e as rotinas do serviço ${ }^{33}$.

Outras açóes fundamentais seriam encaminhar a família para profissionais de serviço social, psicologia e apoio espiritual e manter interdisciplinaridade com estes; assistir à máe nas suas necessidades; estabelecer relacionamento empático; ser paciente e gentil; ouvir com atenção, interesse e tolerância; e procurar entendê-la e aceitá-la. O estabelecimento de um relacionamento terapêutico da equipe de saúde com essa mãe pode aliviar sua ansiedade, seu medo da incerteza e sua carga emocional e, consequentemente, reduzir o estresse de todos os personagens envolvidos ${ }^{33}$.

Uma febre alta, que pode variar de $38^{\circ}$ a mais de $40^{\circ} \mathrm{C}$, associada ou não a tremores e calafrios, e que se manifesta de horas após a infusão do enxerto até por volta do dia +5 , ou se estender até o dia +14 , pode ser resultante não de um processo infeccioso, mas da alorreação dos linfócitos $T$, tanto do paciente quanto do doador. Esse processo libera na circulação sanguínea uma série de citocinas inflamatórias, principalmente a interleucina- 6 (IL-6), caracterizando a chamada síndrome de liberação de citocinas $(\mathrm{SLC})^{35}$.

Essa síndrome é graduada e varia de sintomas de pouco risco como febre, náuseas, fadiga e mal-estar; passa por hipotensão e insuficiência respiratória; alteraçóes das funçôes hepática e renal; e pode evoluir para alteraçôes cardíacas, neurológicas, falência de múltiplos órgãos e morte ${ }^{35}$. Costuma ser mais incidente nos casos que foram enxertados com sangue periférico, uma vez que esse tipo de enxerto possui um quantitativo bem maior de células $\mathrm{T}$ do que os de medula óssea ${ }^{29,35}$.

O grau mais leve pode ter uma alta prevalência: $83 \%$ no estudo de Arango e Combariza ${ }^{12}$ e $100 \%$ no estudo de Sugita et al. ${ }^{8}$, mas os graus mais severos, ainda que menos frequentes, podem conferir um mau prognóstico aos pacientes ${ }^{35}$. Contudo, a maioria dos pacientes costuma remitir da febre poucos dias após a administração da ciclofosfamida pós-transplante, uma vez que ela trata a causa da síndrome inativando os linfócitos $\mathrm{T}$ e interrompendo a liberação das citocinas ${ }^{12}$.

A importância para a enfermagem é que, em caso de febre, seja por SLC ou náo, o protocolo para neutropenia febril foi e deverá ser instituído visando à prevenção da sepse $^{11,31}$. Mesmo que o paciente se apresente com sinais de inflamação, o uso de glicocorticoides não deverá ser feito até o dia +5 , salvo a critério médico ${ }^{1,8,12}$. A monitorização das funçôes cardíacas, respiratórias, renais, hepáticas, e neurológicas nos pacientes febris por intermédio da verificação sistemática de sinais vitais, saturação de oxigênio, controle hídrico, peso corporal e nível de consciência deverá ser constante e quaisquer alteraçóes prontamente comunicadas à equipe médica.

A literatura e os resultados desta revisão mostram que a infecção é a segunda causa isolada de morte nos TCTH alogênicos, ficando atrás apenas da recaída da doença. A enfermagem tem um papel crucial no seu controle e, no sentido de contribuir para diminuir sua estatística, deve implantar açôes educativas e rotinas operacionais para prevenção de infecções no ambiente hospitalar ${ }^{36}$.

Conforme estudos pré-clínicos, a ciclofosfamida não atua em células que estão em repouso. Portanto, essa plataforma poupa linfócitos jovens não alorreativos, linfócitos $\mathrm{T}$ de memória e linfócitos $\mathrm{T}$ reguladores, o que é fundamental na reconstituição imunológica do paciente após o haplo. Mais importante ainda é que não afeta as células-tronco hematopoéticas. Estas contêm uma grande quantidade da enzima aldeído desidrogenase e isso as torna resistentes à ação da droga. Dessa forma, a recuperaçấo hematológica não é comprometida ${ }^{1}$.

Nos estudos desta revisáo, a quase totalidade dos pacientes recuperou os neutrófilos em uma média de $13^{14}$ a $21^{18}$ dias pós-transplante. Contudo, o estudo de Rashidi et al. ${ }^{17}$ discutiu que a pega neutrofílica e a recuperação imunológica celular e humoral no haplo podem ser mais lentas em razão das incompatibilidades no HLA e das plataformas diferenciadas de imunossupressão. Portanto, mesmo após a pega e até às fases mais tardias, como em todos os tipos de TCTH, eles permanecem sujeitos a infecçôes por uma série de bactérias, fungos, protozoários e vírus respiratórios e intestinais, sazonais ou não ${ }^{36}$.

Embora o EBV, o adenovírus, o herpes simples, o herpes humano 6 e outros vírus tenham sido relatados nos estudos revisados, o CMV e o BK foram os mais descritos em $48 \%$ e $56 \%$ das amostras, respectivamente. Esses patógenos podem causar pneumonias e doenças viscerais letais, além de cistites hemorrágicas prolongadas e de difícil controle ${ }^{32,36}$.

O estudo de Slade et al. ${ }^{21}$, com 104 pacientes, mostrou que a infecção foi a causa primária de morte em 12\% deles e secundária em $41 \%$. Além de infecçôes bacterianas e fúngicas, foram encontradas $54(76 \%)$ reativaçóes de CMV em 71 pacientes soropositivos. Destes, 15\% apresentaram doença visceral: sete intestinais, seis pulmonares e dois em ambas as localizaçóes. $\mathrm{O}$ vírus $\mathrm{BK}$ 
foi reativado em 33 pacientes e, destes, 20 (19\% do total) apresentaram cistite hemorrágica. Também ocorreram reativaçóes de herpes-vírus em sete pacientes e 16 casos de infecçōes por vírus respiratórios sazonais.

Um outro exemplo é o estudo brasileiro de Bonfim et al. ${ }^{23}$ com 30 pacientes portadores de anemia de Fanconi submetidos ao haplo, em que $75 \%$ reativaram o CMV e $50 \%$ apresentaram cistite hemorrágica. A grande maioria dessas complicaçóes ocorreu na fase pós-pega. Pneumonia intersticial por CMV, toxoplasmose e adenovirose disseminada contribuíram para a morte em três casos.

A enfermagem deve intensificar suas açôes educativas aos pacientes e familiares quanto às medidas de controle de infecçóes, principalmente, a adequada lavagem das mãos, e sinais e sintomas que devem ser reportados com prontidão caso ocorram ${ }^{36}$. Lembrando que o paciente de haplo já pode ter tido alta hospitalar, os profissionais que trabalham nos ambulatórios ou hospitais-dia devem manter uma abordagem criteriosa e um olhar mais diferenciado sobre esse paciente quanto a essas complicaçóes.

A anamnese deve investigar objetivamente alteraçóes respiratórias, intestinais e urinárias com questôes diretas sobre tosse, cansaço aos esforços, expectoraçôes e suas características, disúria, polaciúria, hematúria, dor abdominal, diarreia etc. O exame físico deve comtemplar o padrão respiratório, a saturação de oxigênio e a presença de ruídos adventícios ou abolidos na ausculta pulmonar ${ }^{36}$. Essas alteraçóes devem ser prontamente comunicadas à equipe médica e de fisioterapia respiratória.

Amostras de secreçôes brônquicas, fezes e urina deverão ser colhidas para pesquisa de vírus em casos sintomáticos. De grande importância é a coleta semanal de sangue para reação em cadeia de polimerase (do inglês, polymerase chain reaction - $\mathrm{PCR}$ ) viral, e/ou antigenemia para o CMV, e a enfermagem deve estar atenta a essa monitorização. A detecção do vírus antes que o paciente se torne sintomático pode nortear um tratamento preemptivo e, com isso, diminuir a possibilidade de infecçóes letais ${ }^{36}$.

Para esse tratamento preemptivo, podem ser prescritas drogas com toxicidades significativas e que requerem cuidados específicos de enfermagem na manipulação, administração e monitorização dos pacientes. Segundo os estudos revisados, para o CMV, foram usados o ganciclovir, mielotóxico ou o foscarnet, nefrotóxico ${ }^{36,10}$. Para o BK e o adenovírus, o cidofovir foi administrado e é também nefrotóxico ${ }^{21,27,30}$. Para o EBV, se empregou o rituximabe, com conhecido potencial para reaçóes de hipersensibilidade ${ }^{10,19,29}$.

A cistite hemorrágica viral resulta em morbidade prolongada, que aumenta o período de hospitalizaçáo, o consumo de hemocomponentes e os custos do transplante. Também acarreta grande sofrimento para os pacientes e familiares e demanda muitas horas de cuidados de enfermagem.

Ela pode se manifestar de dias a meses após o haplo; por exemplo, no estudo de Bonfim et al. ${ }^{23}$, ela se apresentou entre os dias $+15 \mathrm{e}+74$. Sua incidência, nesta revisão, variou de $7 \%$ a $50 \%{ }^{7,30,23}$, enquanto Rimondo et al. ${ }^{30}$ referiram uma variaçáo, na literatura, entre $4 \%$ e $75 \%$. Os vírus $\mathrm{BK}$ foram os principais agentes etiológicos, mas ela também foi causada pelos vírus John Cunningham (JC) e adenovírus ${ }^{10,27,29,30}$.

Até o momento, o aspecto profilático da complicação ainda não está definido. $\mathrm{O}$ uso de quinolonas em pacientes com BK positivo foi empregado porque essas drogas inibem a replicação viral ${ }^{21,27,30}$. Entretanto, não existe ainda um consenso sobre essa intervençáo, uma vez que nem todos os pacientes positivos vão desenvolver cistite hemorrágica e, além do mais, esses antibióticos podem induzir o surgimento de bactérias multirresistentes ${ }^{32}$.

No que diz respeito ao tratamento, as intervençóes com recomendaçóes mais fortes continuam sendo as medidas de suporte como hidratação e analgesia adequadas; transfusão de hemácias e plaquetas para corrigir anemia e diminuir o sangramento e irrigação vesical contínua com solução salina para evitar obstrução. Na ocorrência desta, poderáo ser realizadas cistoscopias para retirada de coágulos $^{32}$. As intervenções com cidofovir endovenoso ${ }^{21,27,30}$; oxigenoterapia hiperbárica; formalização da bexiga; e a infusão vesical de soluçóes à base de alúmen, nitrato de prata, hialuronato sódico, prostaglandinas, fator estimulador de colônias de macrófagos e granulócitos (GM-CSF), cidofovir e cola de fibrina têm sido relatadas como efetivas, mas as evidências ainda são limitadas ${ }^{32}$.

Um grande desafio que a cistite hemorrágica infecciosa prolongada apresenta para a enfermagem é que a cateterizaçáo vesical de demora para irrigação pode ter que ser repetida várias vezes em decorrência de obstrução e demandar o uso de cateteres cada vez mais calibrosos. Isso pode causar irritaçôes e lesôes no trato urinário, além de aumentar o risco de infecçóes bacterianas associadas. Portanto, o intercâmbio da equipe de transplante com um médico urologista é fundamental.

As açôes de enfermagem devem estar direcionadas para o controle adequado da dor; manutençáo do conforto e higiene do paciente; monitorização do controle hídrico; descrição do aspecto da drenagem vesical e da presença de coágulos; acompanhamento dos níveis diários do hemograma; transfusão de plaquetas antes e/ou após as cateterizaçôes; posição e fixação do cateter de forma a evitar tracionamentos; medidas de controle de infecçóes nas manipulaçóes do sistema; ordenha do cateter e do ducto coletor em caso de obstruçóes; educação do paciente e de seus cuidadores para evitar manipular qualquer parte 
do sistema, solicitando ajuda profissional sempre que necessário e encaminhá-los para apoio psicológico. A fim de evitar desconfortos, é aconselhável que a irrigação seja com soluçáo salina em fluxo gravitacional e à temperatura ambiente ${ }^{32}$, salvo outras recomendaçóes específicas do urologista.

Os estudos que integraram esta revisão foram, em sua maioria, observacionais retrospectivos e compostos por amostras pequenas; isso, sem dúvida, é uma limitação quando se pretende avaliar os resultados de uma determinada intervenção. Todavia, observou-se que, nos estudos com amostras pequenas, os autores foram mais detalhistas quanto à descrição do processo, das características e das complicaçóes e, por isso, foram fundamentais para o alcance dos objetivos traçados.

O presente estudo também tem suas limitaçōes. Em primeiro lugar, o fato de ter sido realizado por apenas uma revisora pode ter acarretado algum prejuízo na confiabilidade e na análise dos dados. Mas a realizaçáo de uma segunda revisão das informaçôes extraídas pode ter minimizado esse problema.

Em segundo, as estratégias de busca podem não ter sido suficientes para identificar estudos de enfermagem. Contudo, buscas anteriores realizadas pela autora com outras finalidades, e em outros bancos de dados, também não apresentaram estudos de enfermagem sobre o tema.

Por último, o fato de a discussão ter sido embasada, em parte, pela experiência pessoal da autora, pode ter gerado tendenciosidades quanto aos temas discutidos. Todavia, eles são frequentes no contexto do haplo com ciclofosfamida pós-transplante e requerem uma maior atençáo por parte das equipes que o realizam.

\section{CONCLUSÃO}

Acredita-se que esta revisão é uma das primeiras a discutir as implicaçôes do haplo com ciclofosfamida pós-transplante para o cuidado de enfermagem. Mesmo com suas limitaçóes, ela pode ser um ponto de partida na educação continuada sobre o tema e uma contribuição útil na construçâo do conhecimento dos profissionais que atuam na área dos TCTH.

Os aspectos que foram discutidos são um alerta para a necessidade de aprimoramento da assistência. Problemas importantes como o processo de administração da ciclofosfamida pós-transplante e a monitorização dos pacientes; o suporte aos doadores; o manejo da febre não infecciosa após a infusão do enxerto; a identificação precoce das infecçóes virais; e o controle dos sintomas e das complicaçóes da cistite hemorrágica devem ser mais completamente investigados, por meio de pesquisas de enfermagem bem desenhadas, para que haja melhora na qualidade de vida dos pacientes e diminuição na morbidade e na mortalidade relacionadas ao haplo.

Diante da grande escassez de estudos específicos de enfermagem sobre o tema, sempre é importante lembrar que resultados negativos podem ser tâo ou mais úteis do que resultados positivos. Dentro de uma modalidade terapêutica nova como o haplo, se podem ocorrer, devem ser divulgados.

\section{CONTRIBUIÇÃO}

A autora participou substancialmente em todas as etapas do trabalho e aprovou a versão final a ser publicada.

\section{DECLARAÇÃO DE CONFLITO DE INTERESSES}

Nada a declarar.

\section{FONTES DE FINANCIAMENTO}

Não há.

\section{REFERÊNCIAS}

1. Kanakry CG, Fuchs EJ, Luznik L. Modern approaches to HLA-haploidentical blood or marrow transplantation. Nat Rev Clin Oncol. 2016;13(1):10-24. doi: https:// doi:10.1038/nrclinonc.2015.128

2. Hamerschlak N. Haploidentical transplantation of hematopoietic stem cells. Rev Assoc Med Bras. 2016;62 (Supl. 1):29-33. doi: http://dx.doi.org/10.1590/18069282.62.suppl1.29

3. Descritores em Ciências da Saúde: DeCS [Internet]. São Paulo (SP): BIREME, OPAS, OMS. 2017 - . Transplante haploidêntico; [acesso 2019 maio 05]. Disponível em: http://decs.bvsalud.org

4. Switzerland B, Fliedner MC. Brief history of HSCT nursing: HSCT nursing through the ages and its evolution. In: Kenyon M, Babic A, editors. The European Blood and Marrow Transplantation textbook for nurses: under the auspices of EBMT. New York: Springer Berlin Heidelberg; c2018. p. xiii-xvii. doi: https://doi. org/10.1007/978-3-319-50026-3.

5. Souza MT, Silva MD, Carvalho R. Revisão integrativa: o que é e como fazer. Einstein. 2010;8(1 Pt 1):102-6. doi: http://dx.doi.org/10.1590/s1679-45082010rw1134

6. Stetler CB, Morsi D, Rucki S, et al. Utilization-focused integrative reviews in a nursing service. Appl Nurs Res. 1998;11(4):195-206. doi: http:// doi: https://doi. org/10.1016/S0897-1897(98)80329-7

7. Castagna L, Crocchiolo R, Furst S, et al. Bone marrow compared with peripheral blood stem cells for haploidentical transplantation with a nonmyeloablative 
conditioning regimen and post-transplantation cyclophosphamide. Biol Blood Marrow Transplant. 2014;20(5):724-9. doi: https://doi.org/10.1016/j. bbmt.2014.02.001

8. Sugita J, Kawashima N, Fujisaki T, et al. HLAhaploidentical peripheral blood stem cell transplantation with post-transplant cyclophosphamide after busulfancontaining reduced-intensity conditioning. Biol Blood Marrow Transplant. 2015;21(9):1646-52. doi: https:// doi.org/10.1016/j.bbmt.2015.06.008

9. Kasamon YL, Bolaños-Meade J, Prince GT, et al. Outcomes of nonmyeloablative HLA-haploidentical blood or marrow transplantation with high-dose posttransplantation cyclophosphamide in older adults. J Clin Oncol. 2015;33(28):3152-61. doi: https://doi. org/10.1200/JCO.2014.60.4777

10. Cieri N, Greco R, Crucitti L, et al. Post-transplantation cyclophosphamide and sirolimus after haploidentical hematopoietic stem cell transplantation using a treosulfan-based myeloablative conditioning and peripheral blood stem cells. Biol Blood Marrow Transplant. 2015;21(8):1506-14. doi: http://dx.doi. org/10.1016/j.bbmt.2015.04.025

11. Bacigalupo A, Dominietto A, Ghiso A, et al. Unmanipulated haploidentical bone marrow transplantation and post-transplant cyclophosphamide for hematologic malignanices following a myeloablative conditioning: an update. Bone Marrow Transplant. 2015;50(Suppl 2):S37-9. doi: http://dx.doi.org/10.1038/ bmt.2015.93

12. Arango M, Combariza JF. Fever after peripheral blood stem cell infusion in haploidentical transplantation with post-transplant cyclophosphamide. Hematol Oncol Stem Cell Ther. 2017;10(2):79-84. doi: http://dx.doi. org/10.1016/j.hemonc.2017.03.001

13. González-Llano O, González-López EE, Ramírez-Cázares AC, et al. Haploidentical peripheral blood stem cell transplantation with posttransplant cyclophosphamide in children and adolescents with hematological malignancies. Pediatr Blood Cancer. 2016;63(11):20337. doi: http://dx.doi.org/10.1002/pbc.26131

14. Jaiswal SR, Chakrabarti A, Chatterjee S, et al. Haploidentical peripheral blood stem cell transplantation with post-transplantation cyclophosphamide in children with advanced acute leukemia with fludarabine-, busulfan-, and melphalan-based conditioning. Biol Blood Marrow Transplant. 2016;22(3):499-504. doi: http:// dx.doi.org/10.1016/j.bbmt.2015.11.010

15. Devillier1 R, Granata A, Fürst $S$, et al. Low incidence of chronic GVHD after HLA-haploidentical peripheral blood stem cell transplantation with post-transplantation cyclophosphamide in older patients. Br J Haematol. 2017;176(1):132-5. doi: https://doi.org/10.1111/ bjh. 13923
16. Gorgeis J, Zhang X, Connor K, et al. T cell-replete HLA haploidentical donor transplantation with posttransplant cyclophosphamide is an effective salvage for patients relapsing after an HLA-matched related or matched unrelated donor transplantation. Biol Blood Marrow Transplant. 2016;22(10):1861-6. doi: http:// dx.doi.org/10.1016/j.bbmt.2016.06.026

17. Rashidi A, Slade M, DiPersio JF, et al. Post-transplant high-dose cyclophosphamide after HLA-matched vs haploidentical hematopoietic cell transplantation for AML. Bone Marrow Transplant. 2016;51(12):1561-4. doi: https://dx.doi:10.1038/bmt.2016.217

18. Devillier R, Bramanti S, Fürst S, et al. T-replete haploidentical allogeneic transplantation using post-transplantation cyclophosphamide in advanced AML and myelodysplastic syndromes. Bone Marrow Transplant. 2016;51(10):194-8. doi: https://doi.org/10.1038/bmt.2015.270

19. Dufort G, Castillo L, Pisano S, et al. Haploidentical hematopoietic stem cell transplantation in children with high-risk hematologic malignancies: outcomes with two different strategies for GVHD prevention. Ex vivo T-cell depletion and post-transplant cyclophosphamide: 10 years of experience at a single center. Bone Marrow Transplant. 2016;51(10):1354-60. doi: https://dx.doi:10.1038/ bmt.2016.16

20. Berger M, Lanino E, Cesaro S, et al. Feasibility and outcome of haploidentical hematopoietic stem cell transplantation with post-transplant high-dose cyclophosphamide for children and adolescents with hematologic malignancies: an AIEOP-GITMO retrospective multicenter study. Biol Blood Marrow Transplant. 2016;22(5):902-9. doi: http://dx.doi. org/10.1016/j.bbmt.2016.02.002

21. Slade M, Goldsmith S, Romee R, et al. Epidemiology of infections following haploidentical peripheral blood hematopoietic cell transplantation. Transpl Infect Dis. 2017;19(1):1-19. doi: https://doi:10.1111/tid.12629

22. Castagna L, Mussetti A, Devillier R, et al. Haploidentical allogeneic hematopoietic cell transplantation for multiple myeloma using post-transplantation cyclophosphamide graft-versus-host disease prophylaxis. Biol Blood Marrow Transplant. 2017;23(9):1549-54. doi: http://dx.doi. org/10.1016/j.bbmt.2017.05.006

23. Bonfim C, Ribeiro L, Nichele S, et al. Haploidentical bone marrow transplantation with post-transplant cyclophosphamide for children and adolescents with Fanconi anemia. Biol Blood Marrow Transplant. 2017;23(2):310-7. doi: http://dx.doi.org/10.1016/j. bbmt.2016.11.006

24. Castagna L, Bramanti S, Devillier R, et al. Haploidentical transplantation with post-infusion cyclophosphamide in advanced Hodgkin lymphoma. Bone Marrow Transplant. 2017;52(5):683-8. doi: http://dx.doi.org/10.1038/ bmt. 2016.348 
25. Srour SA, Milton DR, Bashey A, et al. Haploidentical transplantation with post-transplantation cyclophosphamide for high-risk acute lymphoblastic leukemia. Biol Blood Marrow Transplant. 2017;23(2):318-24. doi: http://dx.doi.org/10.1016/j. bbmt.2016.11.008

26. Bashey A, Zhang MJ, McCurdy SR, et al. Mobilized peripheral blood stem cells versus unstimulated bone marrow as a graft source for T-cell-replete haploidentical donor transplantation using post-transplant cyclophosphamide. J Clin Oncol. 2017;35(26):3002-9. doi: https://doi.org/10.1200/JCO.2017.72.8428

27. Klein OR, Buddenbaum J, Tucker N, et al. Nonmyeloablative haploidentical bone marrow transplantation with post-transplantation cyclophosphamide for pediatric and young adult patients with high-risk hematologic malignancies. Biol Blood Marrow Transplant. 2017;23(2):325-32. doi: http:// dx.doi.org/10.1016/j.bbmt.2016.11.016

28. Llosa NJ, Cooke KR, Chen AR, et al. Reduced-intensity haploidentical bone marrow transplantation with post-transplant cyclophosphamide for solid tumors in pediatric and young adult patients. Biol Blood Marrow Transplant. 2017;23(12):2127-36. doi: https://doi. org/10.1016/j.bbmt.2017.08.012

29. Esquirol A, Pascual MJ, Ortiz M, et al. Single-agent GVHD prophylaxis with tacrolimus after posttransplant high-dose cyclophosphamide is a valid option for haploidentical transplantation in adults with hematological malignancies. Bone Marrow Transplant. 2017;52(9):1273-79. doi: https://doi.org/10.1038/ bmt.2017.111

30. Rimondo A, Crocchiolo R, El-Cheikh J, et al. The calcineurin inhibitor and the intensity of the conditioning regimen may affect the occurrence of polyomavirusassociated hemorrhagic cystitis after haploidentical hematopoietic stem cell transplantation with posttransplant cyclophosphamide. Bone Marrow Transplant. 2017;52(1):135-7. doi: https://doi.org/10.1038/ bmt.2016.193

31. Kwon M, Bautista G, Balsalobre P, et al. HaploCord transplantation compared to haploidentical transplantation with post-transplant cyclophosphamide in patients with AML. Bone Marrow Transplant. 2017;52(8):1138-43. doi: https://doi.org/10.1038/ bmt.2017.36

32. Wallhult E, Quinn B. Early and acute complications and the principles of HSCT nursing care. In: Kenyon M, Babic A, editors. The European Blood and Marrow Transplantation textbook for nurses: under the auspices of EBMT. New York: Springer Berlin Heidelberg; c2018. p. 163-196. doi: https://doi.org/10.1007/978-3-31950026-3_9

33. Castagna A, Mcmonagle L, Eeltink Cand, et al. Transplantation through the generations. In: In: Kenyon
M, Babic A, editors. The European Blood and Marrow Transplantation textbook for nurses: under the auspices of EBMT. New York: Springer Berlin Heidelberg; c2018. p. 135-161. doi: https://doi.org/10.1007/978-3-31950026-3_8

34. Halter J, Kodera Y, Ispizua AU, et al. Severe events in donors after allogeneic hematopoietic stem cell donation. Haematologica. 2009;94(1):94-101. doi: https://doi. org/10.3324/haematol.13668

35. Abboud R, Keller J, Slade M, et al. Severe cytokinerelease syndrome after $\mathrm{T}$ cell-replete peripheral blood haploidentical donor transplantation is associated with poor survival and anti-IL-6 therapy is safe and well tolerated. Biol Blood Marrow Transplant. 2016;22(10):1851-60. doi: https://doi.org/10.1016/j. bbmt.2016.06.010

36. Murray J, Agreiter I, Orlando L, et al. BMT Settings, infection and infection control. In: Kenyon M, Babic A, editors. The European Blood and Marrow Transplantation textbook for nurses: under the auspices of EBMT. New York: Springer Berlin Heidelberg; c2018. p. 97-134. doi: https://doi.org/10.1007/978-3-319-50026-3_7

Recebido em 22/7/2019 Aprovado em 26/12/2019 